\title{
A case of Proteus syndrome with a large atrial septal defect
}

\author{
Kariyawasam JP ${ }^{1}$, Kankananarachchi $\mathbf{I}^{1}$, Naotunna $\mathbf{C}^{1}$, Wakwella HC ${ }^{1}$, Gunawardane TPJ ${ }^{1}$, \\ Gunasekara $\mathbf{C}^{2}$ \\ ${ }^{1}$ University Paediatric Unit, ${ }^{2}$ Paediatric Cardiology Unit, Teaching Hospital Karapitiya, Galle, Sri Lanka.
}

\author{
Correspondence: Dr. J. Prathibha Kariyawasam \\ e-mail: prathibhaka85@gmail.com \\ (D) https://orcid.org/0000-0002-7404-8264 \\ Submitted on 31.05.2021 and accepted for publication on 10.08.2021
}

\section{Introduction}

Proteus syndrome is named after the Greek god 'Proteus - meaning 'polymorphous' to characterise the variable and changing phenotype of this condition. It was first described by Cohen and Hayden in 1979. Only limited literature is available globally (1). The estimated prevalence is $<1 /$ $1,000,000$ live births (2).

It is inherited as a somatic mutation in the oncogene AKT1 encoding an enzyme (AKT 1 kinase) mediating cell proliferation and apoptosis. AKT1 kinase regulates cell growth proliferation, differentiation and cell survival $(1,3)$. As a result of the mutation, there is an alteration of local production or regulation of tissue growth factor receptors causing abnormal growth in a patchy or segmental distribution. The disease affects bone, connective tissue, fatty tissue, skin, central nervous system and internal viscera.

Most of the time, these patients are born normal at birth and show progressive changes of growth postnatally within 6 to 18 months coming to a plateau in the adolescence (4).

Herein, we report a child whose abnormal physical features were not detected until 12 years of age. She has features suggestive of Proteus syndrome with another rare association of this syndrome, a cardiac defect.

\section{Case presentation}

A 12-year-old apparently healthy girl from a rural low-income family was referred to the paediatric cardiology clinic for further evaluation of a systolic murmur detected at the school medical inspection. She is the third born to healthy non-consanguineous parents of a low-income family. She was born at term via normal vaginal delivery with a birth weight of $3000 \mathrm{~g}$. Her antenatal period had been uneventful. Her neonatal period and throughout, up to the presentation has been free of medical or surgical problems except for one episode of lower respiratory tract infection and wheezing at three years of age. She attends the local government school and has average school performance. Her development history and immunization coverage are age appropriate and the family history does not give any significant detail in relation to her condition.

Examination revealed a girl with no facial dysmorphism, weight at $10^{\text {th }}$ to $25^{\text {th }}$ centile, height at $3^{\text {rd }}$ to $10^{\text {th }}$ centile (within mid parental height), body mass index of $17 \mathrm{~kg} / \mathrm{m}^{2}$ ( $25^{\text {th }}$ to $50^{\text {th }}$ centile). The most striking features were webbed neck (Figure 1), scoliosis, and two large cystic lumps over the back of the chest (Figure 2) which were said to be congenital and non-progressive, a sacral pit and a small epidermal naevus just lateral to the sacral pit. Cardiovascular system showed normal blood pressure for her age with a fixed split in $2^{\text {nd }}$ heart sound. There was a grade three ejection systolic murmur at the left upper sternal edge. 
Her respiratory and abdominal examination revealed normal findings. She was in Tanner stage 3 in her pubertal development. Her body habitus was unusual with wasting of the left side of the body and hemihypertrophy of the right side (Figures 1 - 4). She had normal intellectual performance and satisfactory social skills.

With regards to investigations, 2D echocardiogram revealed a large ostium secundum atrial septal defect (ASD) shunting left to right, dilated right atrium and right ventricle without significant pulmonary hypertension (Figure 5). Skeletal survey revealed bilateral cervical ribs and scoliosis.

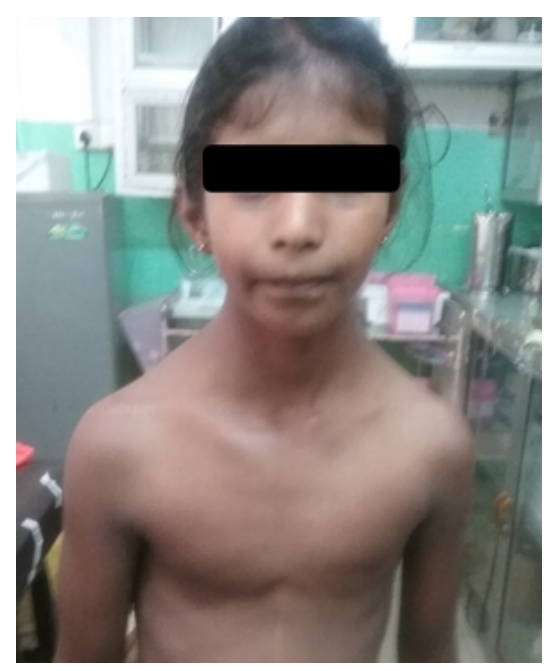

Figure 1: Webbed neck and proteus syndrome facial features

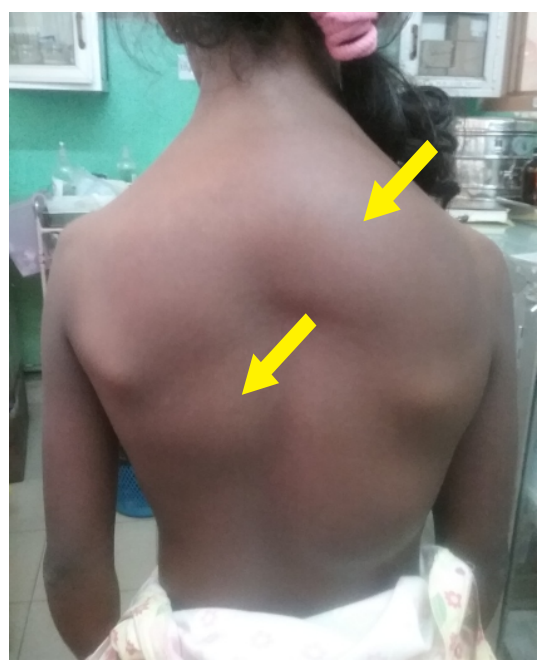

Figure 2: Two large cystic lumps (yellow arrows) over the back of the chest

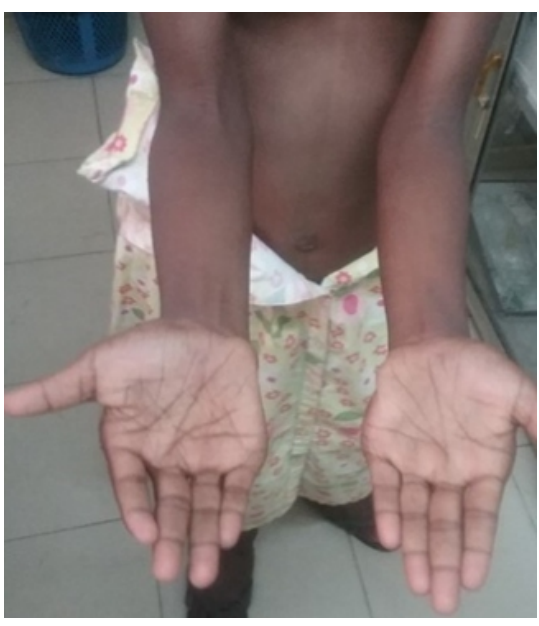

Figure 3: Upper limb wasting of the left side with hemihypertrophy on the right side

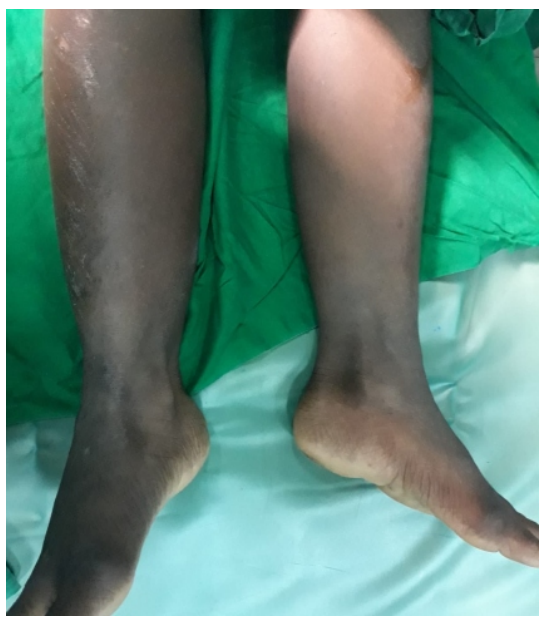

Figure 4: Lower limb wasting of the left side with hemihypertrophy on the right side

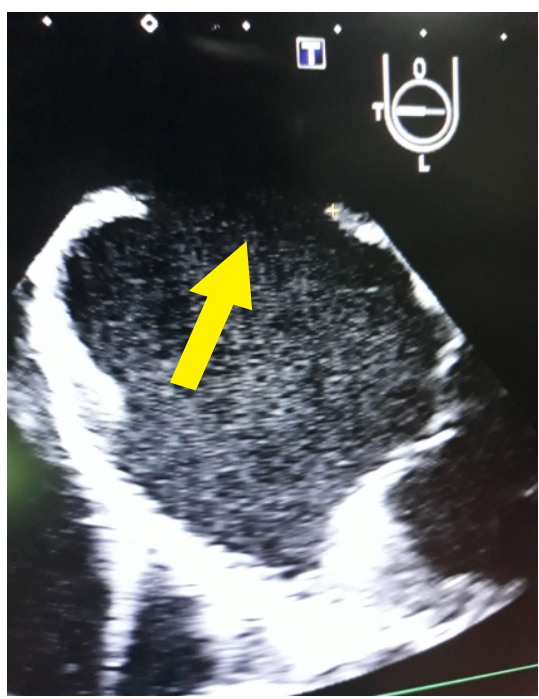

Figure 5: Transesophageal echocardiogram (TOE) showing large OS ASD $(20 \mathrm{~mm})$ (yellow arrow) 
Table 1: Revised diagnostic criteria for Proteus syndrome

\begin{tabular}{lc}
\hline To make a diagnosis of PS, one must have all the general criteria, and various specific criteria \\
\hline General criteria & Specific criteria \\
All the following: & Either: \\
- Mosaic distribution of lesions & - Category A or \\
- Sporadic occurrence & - Two from category B or \\
- Progressive course & - Three from category C \\
\hline
\end{tabular}

\section{Specific criteria categories}

A. 1. Cerebriform connective tissue naevus

B. 1. Linear epidermal naevus

2. Asymmetric, disproportionate overgrowth One or more:
(a) Limbs
(b) Hyperostosis of the skull
(c) Hyperostosis of the external auditory canal
(d) Maga spondylo dysplasia
(e) Viscera: spleen / thymus

C. 1. Dysregulated adipose tissue

Either one:

(a) Lipomas

(b) Regional lipohypoplasia

2. Vascular malformations

One or more:

(a) Papillary malformation

(b) Venous malformation

(c) Lymphatic malformation

3. Lung cyst

4. Facial phenotype

All:
(a) Dolichocephaly
(b) Long face
(c) Down slanting palpebral fissures and / or ptosis
(d) Low nasal bridge
(e) Wide or anteverted nares
(f) Open mouth at rest

Ultrasound scan over the lumps were suggestive of cystic hygroma extending from the back of the neck. Pelvic ultrasound showed small uterus and ovaries.

Her karyotype was 46, XX. Nerve conduction studies were normal and her MRI brain and spine excluded any malformations. Considering the presence of hemihypertrophy, skeletal abnormalities, lymphatic malformations, skin manifestations and hypoplastic uterus, the clinical diagnosis was made as Proteus Syndrome. The mutation analysis was not done due to financial constraints. The child underwent ASD device closure without any complications.

\section{Discussion}

According to the Biesecker and colleague's consensus criteria set forth in 1999 and revised in 2006, when establishing the diagnosis of Proteus syndrome clinically, general and specific criteria should be fulfilled $(3,5)$ (Table 1$)$.

To diagnose Proteus syndrome clinically, all the general criteria and one specific criterion from category A; or two specific criteria from category B; or three specific criteria from category $\mathrm{C}$ is required. Apart from general criteria, our patient satisfied category $\mathrm{B}$ with the presence of epidermal naevus and asymmetric, disproportionate overgrowth of $\geq 1$ of limbs. 
When clinical criteria do not fulfill the diagnosis, identification of pathogenic variant in AKT1 by molecular genetic testing in affected tissue parts is recommended.

Proteus syndrome, due to it's complexity and variability in presentation can be easily missed as already happened in this case. Even though there had been progressive hemi hypertrophy, enlargement of cystic lesions on the back, no attempt was made to diagnose the condition in previous health care encounters until she presented with a large ASD. Cardiac abnormalities are rare in this syndrome unlike in Sotos syndrome which is also a paediatric overgrowth syndrome with congenital heart defects (e.g. ASD, VSD). Some studies on echocardiography / cardiac MRI findings in proteus syndrome have shown that fatty infiltration of intraventricular septum $(6,7)$, but index case did not reveal any abnormal cardiac finding in myocardium on her echocardiogram. She did not reveal any cardiac arrhythmias clinically or on her 12 lead ECG. She had a large OS ASD with evidence of right sided volume overload. She underwent an ASD device closure successfully without any complications.

Management of skeletal overgrowth and connective tissue naevi which are disfiguring and affecting mobility and functioning needs orthopaedic, dermatological and plastic surgical assistance.

As in our child, more than two thirds of patients with Proteus syndrome have normal intellectual functions. But there are reported cases with hydrocephalus, hemimegaloencephaly, absent corpus callosum and craniosynostosis (4). One case reported previously in Sri Lanka some years back had hemimegalencephaly (8). Being a sporadic mutation and low fertility rate in patients warrant no inheritance of the syndrome in families. Proteus syndrome is one condition with several other overlapping syndromes that carry the risk of having loss of function gene mutations in a tumour suppressor gene (PTEN). These similar syndromes are named PTEN Hamartoma Tumour Syndromes. Therefore, patients diagnosed to have Proteus syndrome should be followed up for malignancy surveillance (9). Most specifically associated tumours are monomorphic adenomas of the parotid glands and bilateral ovarian cystadenomas (2). Not only tumours but there are other complications; progressive skeletal deformities, invasive lipomas, deep vein thrombosis and pulmonary embolism (10).

With developments in genetic studies, we now have facilities to detect AKT1 pathogenic variant in cultured amniocytes in suspected fetuses with segmental overgrowth, skeletal and CNS abnormalities (11).

\section{Conclusions}

Presence of unusual physical features of a child warrants proper clinical evaluation and investigations which will aid the diagnosis. Conditions like, the Proteus syndrome if diagnosed early can be managed with multidisciplinary involvement and timely interventions. As such syndromes are not usually detected antenatally or at birth progressive changes can be only picked up if proper examination is done during medical encounters. Disfiguring conditions with associated complications including malignancy in a child needs appropriate counseling and proper long term follow up.

The informed written consent of the parents has been obtained to publish this case report with photographs of the child.

\section{References}

1. Minglin Ou, Zhaojun Sun, Peng Zhu, Guoping Sun, Yong Dai, Proteus syndrome: A case report and review of the literature. Molecular and Clinical Oncology, 2017; 6(3): 381-383. https://doi.org/10.3892/mco.2017.1140

2. Biesecker L. The challenges of Proteus syndrome: diagnosis and management. European Journal of Human Genetics. 2006; 14: 1151-1157. http://www.nature.com/ejhg/journal/v14/n11/pdf/ 5201638a.pdf.

3. Proteus syndrome - Gene Review: Biesecker LG, Sapp JC Available from: https://rarediseases.info.nih.gov/ diseases/7475/proteus-syndrome.

4. Linton JA, Seo BK, Oh CS. Proteus syndrome: a natural clinical course of Proteus syndrome. Yonsei Med J. 2002 Apr; 43(2): 259-266. doi: 10.3349/ymj.2002.43.2.259. 
5. Newly iagnosed. Proteus Syndrome Foundation. Available from: http://www.proteus-syndrome.org/newlydiagnosed.html.

6. Hannoush H, Sachdev V, Brofferio A, Arai AE, LaRocca G, Sapp J, Keppler-Noreuil KM. (2015). Myocardial fat overgrowth in Proteus syndrome. American Journal of Medical Genetics Part A. 2015: 167(1): 103-110.

7. Dorit Koren, Andrew Palladino, in Genetic Diagnosis of Endocrine Disorders: Sotos syndrome (Second Edition), 2016.

8. De Silva M, Jayantha U, Hapuarachchi G, and Hewawitharana G, 2009. A case of Proteus syndrome (elephant man). Ceylon Medical Journal, 51(1): p.38 DOI: http://doi.org/10.4038/cmj.v51i1.1378.
9. Smith's Recognizable Patterns of Human Malformations, $7^{\text {th }}$ edition, p678-679.

10. Xi-Bao Zhang, Chang-Xing Li, Yu-Qing He, San-Quan Zhang, Yan-Xia Cai. Proteus syndrome: a case report and a case study review in China. Dermatol Reports. 2010; 2(1): e3. doi: 10.4081/dr.2010.e3.

11. Abell K, Tolusso L, Smith N, Hopkin R, Vawter-Lee M, Habli M, Riddle S, Calvo-Garcia MA, Guan Q, Bierbrauer $\mathrm{K}$, Hwa V. Prenatal diagnosis of Proteus syndrome: Diagnosis of an AKT1 mutation from amniocytes. Birth Defects Research. 2020 Nov; 112(19): 1733-1737. 